\title{
Albanon
}

Revistë kulturore

\section{Automobilat e parë në Shqipëri në fillim të shek.XX}

Roald A. Hysa

\section{Transporti modern, komunikimi dhe automobilat}

Transportet dhe komunikimi në erën e re të shek. XX në të cilën hyri Shqipëria nuk ishin aq të zhvilluara, për shkak edhe të një infrastrukture të varfër dhe të pazhvilluar në drejtimin e duhur. Telegrafi ishte i vetmi mjet komunikimi ndërmjet qyteteve shqiptare, pjesërisht linja hekurudhore lidhte Shkupin me Manastirin, me Selanikun e më tej me Stambollin. Sistemi rrugor ekzistues normalisht që nuk mund t’i përgjigjej mjeteve të reja të transportit të automobilave, të cilët kërkonin kushte të veçanta, pra rrugë me asfalt. Një pjesë e këtij sistemi kishte nisur të ndërtohej pas fillimit të Luftës së Parë Botërore nga fuqitë e ndryshme që zaptuan trojet shqiptare, ku italianët dhe austrohungarezët kishin synime qëndrimi aftatgjata në Shqipëri dhe për pasojë për nevojat e ngutshme ushtarake nisën investimet në rrugët, dhe austrohungarezët edhe në dekovilet për të pasur një lëvizje të shpejtë të trupave dhe të materialit ushtarak; rrjeti i dekovileve më pas do të prishej me tërheqjen e austriakëve. Rrugë të reja u hapën gjatë Luftës së Madhe vetëm se nuk e mbulonin të gjithë territorin, ndërkohë që për Shqipërinë problemi më i madh atë kohë e deri më 30 korrik 1926, ka qenë rregullimi përfundimtar i kufijve me fqinjët, datë kur do të nënshkruhej akti final i caktimit të kufijve të Shqipërisë në Paris në Konferencën e Ambasadorëve me praninë e ambasadorëve të Britanisë së Madhe, Francës, Italisë dhe të Japonisë dhe prej delegatëve të Shqipërisë, Greqisë e Jugosllavisë${ }^{1}$. Ky dokument ishte i një vlere jetike për Shqipërinë, duke shmangur mosmarrëveshjet e mëtejshme kufitare dhe duke rritur stabilitetin e vendit në rajon. Stabiliteti i qeverisjes

1 Selenica Teki, Shqipria më 1927, Shtypshkronja “Tirana", Tiranë 1929, fq. 153. 


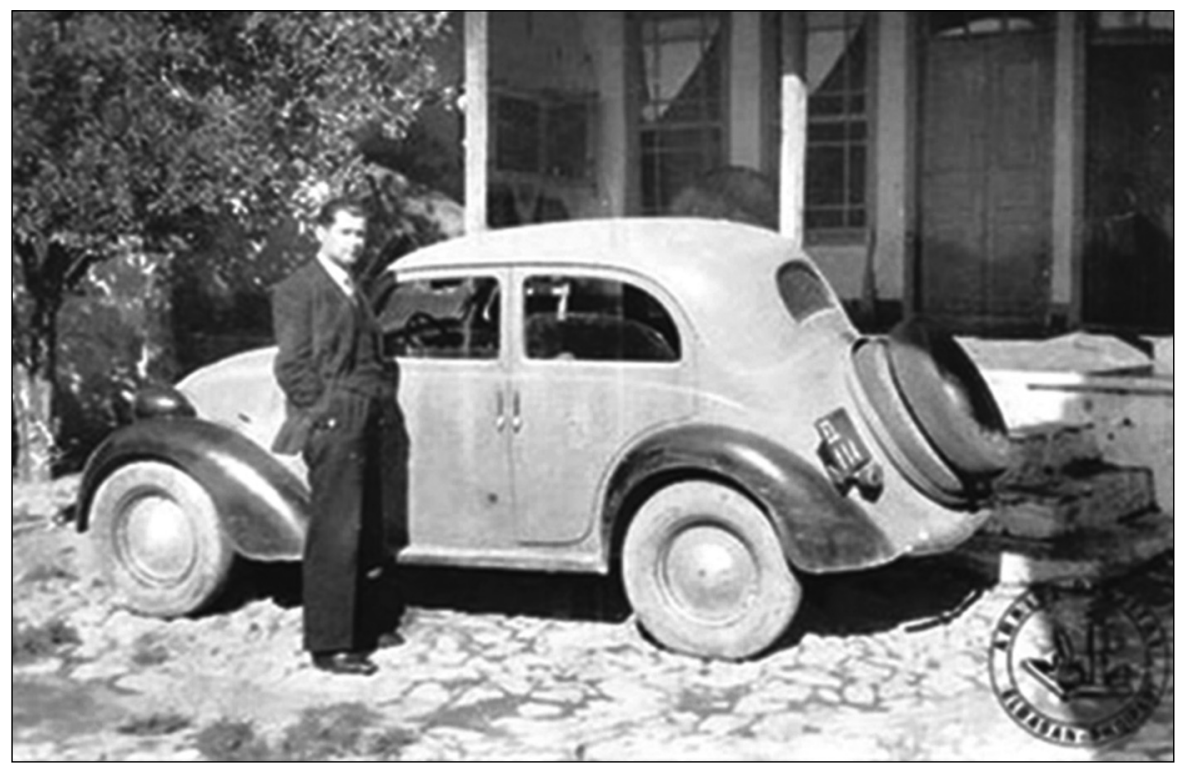

Autovetura e parë në Elbasan e vëllezërve Garunja në Kala

i hapte rrugën zhvillimeve të mëtejshme modernizuese bashkëkohore, ku hyjnë rrugët, mjetet e reja të transportit dhe komunikimi.

\section{Kur hynë automobilat e parë}

Në një foto të vjetër të vitit të largët 1913 na jepet një automobil italian pranë xhamisë së Sulejman Pashës dhe në diçiturën shoqëruese të kësaj fotoje shkruhet "1913: Italianët arrijnë në Shqipëri më automjetin e parë që mund të jetë shikuar në vend" (Photo by Hulton Archive/Getty Images) ${ }^{2}$. Automobilat dhe aeroplanët në Shqipëri shfaqen kryesisht gjatë Luftës së Parë Botërore në përbërje të formacioneve luftarake transportuese të ushtrive të huaja, që zaptuan territoret shqiptare. Në nëntor të vitit 1915 trupat serbe hyjnë në Elbasan dhe oficerët serbë hyjnë të shoqëruar nga një automobil, dhe më pas në ndjekje të tyre vijnë trupat ushtarake bullgare, ku në Fushë Mbret të Elbasanit ulet një avion ushtarak bullgar³.

Zhorzh Prevo një reporter lufte në frontin e Lindjes gjatë Luftës së Madhe

2 https://www.gettyimages.com.au/detail/news-photo/italians-arrive-in-albania-withthe-first-vehicle-to-be-news-photo/3264226

3 Dylgjeri, Bukurosh. Pak Histori, Elbasani 1913-1937, https://elbasaniad.org/pakhistori-elbasan-1913-1937/ 


\section{Albanon}

\section{Revistë kulturore}

na tregon për udhëtimin e tij nëpër Shqipëri me automobil gjatë vitit 1917 në një revistë të ilustruar e specializuar për automobilat (Automobilat në Ushtri). Pasi ka arritur në Follorinë me avion dhe meqë ishte e rrezikshme të vazhdoje asokohe udhëtimin në ajër ai i drejtohet Korçës me automobil në rrugë tokësore, të cilat akoma nuk ishin të përshtatshme për këto mjete moderne. Ai përmend edhe përdorimin e një traktori të markës franceze Latil në shërbim të skuadronit, që e shoqëronte Zhorzh Prevonë ${ }^{4}$. Në fotot ilustruese shohim ushtarakë italianë pranë një automobili në luginën e Devollit dhe një foto ku shihen edhe avionët e një skuadrilje ajrore luftes Ky reportazh përshkruan zonat e luftës dhe ndarjet e tyre midis italianëve, austriakëve dhe francezëve, si dhe zakonet dhe traditat e disa pjesëve të Shqipërisë, ku Korça ka pasur vëmendjen kryesore të këtij reporteri lufte.

Me mbarimin e "Luftës së Madhe" nisin edhe përpjekjet e para për modernizimin e vendit, e sidomos të qyteteve kryesore si Durrësi, Tirana, Elbasani. Në vitin 1922 qeveria e Tiranës kishte në dispozicion të saj edhe automjete, ashtu si na njofton udhëtarja amerikane Rose Wilder Lane. Ajo udhëton nga Shkodra për në Tiranë në marsin e vitit 1922 me një "Ford trimosh", kurse bagazhet ua mori pa pagesë shoferi i një kamioni qeveritar ${ }^{6}$, dhe njëkohësisht na njofton gjatë qëndrimit të saj në Tiranë, se Ministria e Brendshme kishte një dinamo me të cilën prodhonte elektricitet. Ndërkaq fillojnë edhe përpjekjet e para në sektorin privat të transportit me krijimin e firmave private, ku në Elbasan janë vëllezërit Garunja, të cilët sjellin fillimisht një veturë (Fiat Millecento) dhe më pas i shtojnë edhe tre kamionë, me gjithë vështirësitë që paraqisnin rrugët kombëtare asokohe, pra, në vitet 1921-19237. Markat më të njohura të automobilave të kohës u importuan qysh në momentet e para, ku dallojnë markat amerikane si Ford, Studebaker, Dodge e ndonjë tjetër, po ashtu edhe ato italiane si Fiat Mileçento, Bianki, si dhe Reno franceze etj. Në aktivitetin e parë automobilistik, që u zhvillua nga shoqëria sportive Vlora në Nartë, më 24 shtator 1929 fitues në kategorinë e parë do të ishte Neki Ramadani me një makinë të tipit "Studebaker" dhe në kategorinë e dytë Gjush Ibrahimi me automobilin e markës Bianki

4 Prévost, Georges. Dans les montagnes d'Albanie, L'automobile aux Armées, Octobre 1917, p. 4.

5 Po aty, fq. 5 dhe 6.

6 Lane, Rose Wilder. Majat e Shalës, Argeta LMG, Tiranë 2004, fq. 215.

7 https://elbasaniad.org/vellezerit-garunja-sollen-makinen-e-pare-ne-qytetin-eelbasanit/

8 Dojka, Ilir. Sporti Shqiptar 1900-1946, West Print, Tiranë 2010, fq. 67. 
Në garën e tretë po në Vlorë, më 1 shtator 1931 morën pjesë 4 makina Fiat, 2 Bianki dhe 2 Reno dhe gara u zhvillua nën patronazhin e princeshës Myzejen Zogu'. Më 28 nëntor 1932 me rastin e 26 vjetorit të shpalljes së Pavarësisë zhvillohet një garë me motoçikleta Tiranë-Durrës e kthim, ndërsa gara e dytë u zhvillua më 2 janar 1934, ku fitues në njërën prej kategorive është Mazllëm Starova me motoçikletën e markës gjermane "N.S.U." me cilindratë $175^{10}$. Një zhvillim i rëndësishëm për kohën do të ishte edhe krijimi i Klubit Turistik dhe Automobilistik Mbretëror KTAM në Tiranë në gusht 1933, që kishte të drejtën të lëshonte dokumente qarkullimi për mjetet automobilistike për shtetasit shqiptarë brenda dhe jashtë vendit, të organizonte aktivitete turistike dhe gara automobilistike ${ }^{11}$. Ndërkaq shohim në një foto të vitit 1924 Irakli Papën me një motoçikletë amerikane Harley Davidson në Sarandë ${ }^{12}$, si dhe dyqanin e gomave amerikane Dunlop të Vasil Papës shpërndarës ekskluziv po në këtë qytet dhe po në këtë vit ${ }^{13}$. Larmia e markave ka të bëjë me shpërndarjen e diasporës shqiptare nëpër botë, ku shqiptarët e Amerikës ishin ata që sollën të parët markat amerikane Ford, Dodge etj., po ashtu edhe Kryqi i Kuq Amerikan, ndërsa pjesa tjetër sipas vendeve ku ishin shkolluar apo edhe që e kishin më të lehtë për të importuar, sidomos nga Italia ndikimi i së cilës në këtë drejtim u ndje pas marrëveshjeve të ndryshme shtetërore italo-shqiptare, por edhe për faktin që komunikimi me Italinë ishte edhe më i shpejtë. Ndikimi italian u ndje fuqishëm edhe në terminologjinë e mekanikës dhe të emërtimit të pjesëve përbërëse të automobilave, një ndikim i cili ndjehet edhe sot e kësaj dite në fjalorin tonë të përditshëm.

\section{Rrugët kombëtare dhe rrjeti i komunikimit}

Shteti Shqiptar në programet e veta ambicioze për ngritjen e një rrjeti komunikimi kombëtar futi edhe ndërtimin e hekurudhave, që paraqiste shumë vështirësi për kohën. Përveç ndërtimit të rrjetit të rrugëve nacionale krahas kemi edhe përpjekjet e ndërtimit të "shemendëferit", pra hekurudhës Durrës Tiranë ${ }^{14}$, por kjo nuk u arrit dot gjatë Shtetit Indipendent. Në gusht

9 Po aty, fq. 68.

10 Po aty, fq. 68.

11 Po aty, fq. 69.

12 Po aty, fq. 70.

13 Po aty, fq. 66.

14 Selenica Teki, Shqipria më 1927, Shtypshkronja "Tirana", Tiranë 1929, fq. 233. 


\section{Albanon}

\section{Revistë kulturore}

të vitit 1922 Mehdi Frashëri do të kërkonte për t’iu përgjigjur nevojave për zhvillim nisjen e projekteve për hekurudhat e ardhshme të Shqipërisë me pikënisje nga portet kryesore të Shëngjinit, Vlorës dhe Sarandës ${ }^{15}$. Me fillimin e një numri të madh punësh botore, ku do të përfshihej edhe ndërtimi i hekurudhës Durrës-Elbasan punimet e së cilës nisën në vitin 1940 dhe në shtypin e kohës u theksua shfaqja "rishtas e Via Egnatias", por që për shkak të luftës u penguan punimet dhe kjo hekurudhë u mbarua nga regjimi komunist me punë vullnetare ${ }^{16}$.

Ndërtimi i rrjetit rrugor ishte një tjetër sfidë për shtetin shqiptar. Sipas zonave ushtarake të ndërhyrjes së huaj gjatë Luftës së Madhe ishin italianët dhe austriakët që ndërtuan rrugë për të lehtësuar komunikimin, po ashtu ishin këto dy fuqi që kishin interesa të drejtpërdrejta materiale për t’u zgjeruar me këto troje. Ndërkaq serbët, malazezët, bullgarët e grekët ishin më të interesuar për të bërë spastrimet e tyre etnike, që pas lufte të krijonin troje me popullsi homogjene ortodokse dhe jo-muslimane.

Në vitet 1916-1920, ushtria italiane çeli e përmirësoi dy trase rrugësh malore, atë të Llogarasë Vlorë-Sarandë $130 \mathrm{~km}$ dhe atë Vlorë-DukatTepelenë-Gjirokastër $110 \mathrm{~km}$, si dhe traktin lidhës Sarandë-DelvinëJergucat-Gjirokastër $60 \mathrm{~km}$. Po ashtu u përmirësuan edhe disa rrugë të tjera si dhe u ndërtuan linja të shkurtra dekovili e linja teleferiku në Vlorë ${ }^{17}$. Në vitin 1916-1918, austro-hungarezët kryen mjaft punime botore në Shqipëri, ku u ndërtuan $650 \mathrm{~km}$ rrugë automjetesh dhe qerresh, një teleferik dhe një linjë dekovili. Dekovili Shkodër-Vorë me degëzimet për Durrës e Tiranë, që vazhdonte në Elbasan e deri në Berat ${ }^{18}$. Pasojat e kësaj lufte ishin katastrofike për popullsinë shqiptare, por menjëherë pas Kongresit të Lushnjes në të gjithë vendin nisin projektet ambicioze të modernizimit, ku dallon ndihma amerikane. Në këtë drejtim ka ndihmuar shumë diaspora shqiptaroamerikane, ku kujtojmë një dyvargësh të Fan Nolit këtu me të cilin i nxiste shqiptaro-amerikanët të investonin në atdhe:

Hajde nëno mos ki frikë,

Se ke djemtë në Amerikë...

Kjo diasporë investoi me projektet e saj private nëShqipëri, ndërkohë që edhe shteti shqiptar ndihmoi në ndërtimin e rrjetit rrugor, që do ta lehtësonte komunikimin

15 Dervishi, Kastriot. Historia e Shtetit Shqiptar 1912-2005, sh. b. 55, Tiranë 2006, fq. 136.

16 Po aty, fq. 441.

17 Po aty, fq. 65.

18 Po aty, fq. 72. 
midis qyteteve të rëndësishme. Në vitin 1921 shteti shqiptar ndërtoi $829 \mathrm{~km}$ rrugë, nga viti 1921 -1928 ndërtoi $483 \mathrm{~km}$ të tjera, si dhe nga viti 1928 kohë kur fillon huaja financiare italiane dhe deri më $1937 \mathrm{u}$ shtuan $850 \mathrm{~km}$ të tjera, pra, në këtë vit kemi gjithsej rrugë kombëtare dhe krahinore 2,202 km¹9.

Mirëpo i gjithë ky rrjet rrugor kishte nevojë edhe për njerëzit dhe jo vetëm për automobilat, ku shifrat e kohës paraqiten shumë interesante, duke i konfrontuar edhe me popullsinë. Në vitin 1927, në qytetet kryesore shqiptare kishte një numër të ndjeshëm automobilash të markave të ndryshme, ku në rang nënprefekture: prefektura e Beratit kishte: Berati 15 automobila (15 shoferë), Lushnja 8 automobila (10 shoferë), Fieri 10 automobila (16 shofera ${ }^{20}$, prefektura e Durrësit vendosi: Durrësi me 34 të tillë (34 shoferë), Shijaku 5 automobila ( 5 shoferë), Kavaja 20 automobila (20 shoferë), dhe Kruja 11 automobila (11 shofera) ${ }^{21}$, prefektura e Elbasanit kishte: Elbasani 17 automobila (17 shoferë), Peqini 8 automobila (8 shoferë) ${ }^{22}$; prefektura e Gjirokastrës vendos: Gjirokastra 25 automobila (44 shoferë), Përmeti 19 automobila (32 shoferë), Delvina 35 automobila (70 shoferë), Libohova 4 automobila (4 shoferë), dhe Çamëria kishte një traktor ${ }^{23}$; prefektura e Korçës vendos: Korça 48 automobila (108 shoferë), Pogradeci 4 automobila (8 shofera) dhe Leskoviku 3 automobila (3 shoferë) ${ }^{24}$; prefektura e Shkodrës kishte: Shkodra 43 automobila (shoferë 43), Malësia e Madhe 2 (shoferë 2), dhe Lezha 2 automobila (shoferë 2) ) $^{25}$; prefektura e Tiranës kishte 85 automobila (85 shoferë); prefektura e Vlorës kishte: Vlora 17 automobila (17 shoferë) dhe Himara 4 automobila ( 8 shoferë ${ }^{26}$ ). Në total për vitin 1927 , kemi në të dhjetë prefekturat e Shqipërisë 419 automobila dhe 562 shoferë. Me termin automobil nënkuptohen edhe veturat, edhe kamionët, të cilët shërbenin edhe për transport mallrash e njerëzish së bashku. Numrin më të madh të automobilave e kishte Tirana me 85, ndërsa numrin më të madh të shoferëve e kishte Korça me 108, dyfishin e automobilave në qarkullim.

19 Shqipënija më 1937, v. II, shtyp. Kristo Luarasi, Tiranë 1938, fq. 197.

20 Selenica Teki, Shqipria më 1927, Shtypshkronja “Tirana”, Tiranë 1929, fq. 187.

21 Po aty, fq. 239.

22 Po aty, fq. 267.

23 Po aty, fq. 304.

24 Po aty, fq. 337.

25 Po aty, fq. 407.

26 Po aty, fq. 483. 